Pacific Journal of Mathematics

TWO EXAMPLES OF AFFINE MANIFOLDS 


\title{
TWO EXAMPLES OF AFFINE MANIFOLDS
}

\author{
WILLIAM M. GoldMaN
}

An affine manifold is a manifold with a distinguished system of affine coordinates, namely, an open covering by charts which map homeomorphically onto open sets in an affine space $E$ such that on overlapping charts the homeomorphisms differ by an affine automorphism of $E$. Some, but certainly not all, affine manifolds arise as quotients $\Omega / \Gamma$ of a domain in $E$ by a discrete group $\Gamma$ of affine transformations acting properly and freely. In that case we identify $\Omega$ with a covering space of the affine manifold. If $\Omega=E$, then we say the affine manifold is complete. In general, however, there is only a local homeomorphism of the universal covering into $E$, which is equivariant with respect to a certain affine representation of the fundamental group. The image of this representation is a certain subgroup of the affine group on $E$, is called the affine holonomy and is well defined up to conjugacy in the affine group. See Fried, Goldman, and Hirsch.

THEOREM. There exists a compact affine manifold $M$ satisfying the following conditions:

(1) $M$ is the quotient of a proper convex domain which is not a convex cone.

(2) $M$ is incomplete and the affine holonomy group leaves invariant no proper affine subspace.

The example we give will be three-dimensional (it is a torus bundle over the circle); by taking products with compact complete manifolds, we obtain similar examples in all dimensions greater than two. The affine holonomy group $\Gamma$ will be solvable; by Fried, Goldman, and Hirsch [3] condition (2) cannot occur if $\Gamma$ contains a nilpotent subgroup of finite index-hence there cannot be any twodimensional examples. There was some hope that the affine holonomy of a compact incomplete affine manifold would necessarily leave invariant an affine subspace; verifying this for similarity structures is the key step in the recent classification of closed similarity manifolds by David Fried [2].

There has also been some work proving, under various hypotheses, that the universal covering of a compact affine manifold, if it is convex, must be a convex cone. If in the universal cover, no geodesic extends infinitely in both directions, it follows from result of Jacques Vey, that the universal cover must be a cone. 
Finally, the above example leads immediately to another somewhat unusual example: if $\Omega$ is the convex universal covering of $M$ above, then the holonomy group $\Gamma$ acts properly and freely on the interior of the complement of $\Omega$ as well; thus we obtain a new affine manifold $\operatorname{int}(E-\Omega) / \Gamma$, which is compact, and has for its universal covering a concave domain which is not the complement of an affine subspace.

The Examples. Consider a parabola in the plane $R^{2}$, say the one given by $y^{2}-2 x=0$. Then the group $G^{\prime}$ of orientation-preserving affine transformations preserving it is the two-dimensional group of affine maps

$$
\left(\begin{array}{cc}
e^{2 s} & e^{s} t \\
0 & e^{s}
\end{array}\right)\left(\begin{array}{c}
\frac{1}{2} t^{2} \\
t
\end{array}\right)
$$

(Here the square matrix denotes the linear part and the collumn vector denotes the translational part of the specified affine map). It is easy to check that $G^{\prime}$ is nonabelian, and acts simply transitively on each of the two open sets

$$
\begin{aligned}
& 0_{+}=\left\{(x, y) \mid y^{2}-2 x>0\right\} \\
& 0_{-}=\left\{(x, y) \mid y^{2}-2 x<0\right\} .
\end{aligned}
$$

The set $0_{+}$is convex although it is not a cone. This should be contrasted to the result of J. L. Koszul [4] that a convex domain in affine space upon which a unimodular group of affine transformations acts transitively must be a cone.

To obtain a compact affine manifold it is necessary to consider the domains $0_{+} \times R$ and $0_{-} \times R$ in $R^{3}$. To do this we add a one-parameter group of translations in the new direction, as well as modify $G^{\prime}$ so as to make the nonunipotent one-parameter subgroup $(t=0)$ exponentially contract in the new direction. Specifically, consider the group $G$ of affine transformations of $R^{3}$ given by

$$
\left(\begin{array}{ccc}
e^{2 s} & e^{s} t & 0 \\
0 & e^{s} & 0 \\
0 & 0 & e^{-s}
\end{array}\right)\left(\begin{array}{c}
\frac{1}{2} t^{2} \\
t \\
u
\end{array}\right)
$$

Clearly $G$ acts simply transitively on $0_{+} \times R$ and $0_{-} \times R$. It is easily checked that $G$ is isomorphic to the Lorentz group $E(1,1)$ which admits discrete cocompact subgroups $\Gamma$, none of which have nilpotent subgroups of finite index.

Since $G$ acts simply transitively on $0_{+} \times R$ (resp. $0_{-} \times R$ ) sub- 
groups $\Gamma$ as above act properly and freely; the quotient $0_{+} \times R / \Gamma$ (resp. $0_{-} \times R / \Gamma$ ) is a compact affine manifold of dimension three having solvable fundamental group. The rest of the assertions in the theorem follow immediately, taking $M=\left(0_{+} \times R\right) / \Gamma$.

The affine manifold $M$ should be contrasted with the following theorem of J. Vey [5]:

TheOREM (Vey). Let $\Omega$ be a convex domain in $E$ and let $\Gamma$ be a group of affine transformations preserving $\Omega$ such that $\Omega / \Gamma$ is compact (but not necessarily Hausdorff). Suppose

(A) $\Omega$ contains no complete line

and one of

(B) $\Omega / \Gamma$ is Hausdorff and $\Gamma$ is discrete

(C) $\Omega$ contains an open cone.

Then $\Omega$ is an open cone.

The domain $\Omega=0_{+}$satisfies (A) but neither (B) nor (C) (taking $\left.\Gamma=G^{\prime}\right)$ and is not an open cone; similarly the domain $\Omega=0_{+} \times R$ satisfies (B) but neither (A) or (C) and is not an open cone. Hence Vey's result is best possible. (Actually, the conclusion of Vey's theorem follows from just hypothesis (C) - for every convex domain is a product $\Omega^{\prime} \times R^{k}$ where $\Omega^{\prime}$ satisfies (A); the result for $\Omega^{\prime}$ then implies the result for $\Omega^{\prime} \times R^{k}$.)

It is interesting to vary to group $G$ with a parameter $p$. By considering the parabola $p y^{2}-2 x=0$ instead, $p \neq 0$, we may replace the group $G$ by the group $G_{p}$ consisting of the affine maps

$$
\left(\begin{array}{ccc}
e^{2 s} & p e^{s} t & 0 \\
0 & e^{s} & 0 \\
0 & 0 & e^{-s}
\end{array}\right)\left(\begin{array}{c}
\frac{p}{2} t^{2} \\
t \\
u
\end{array}\right)
$$

Since all parabolas are affinely equivalent, the groups $G_{p}(p \neq 0)$ are all conjugate subgroups of the affine group. However, as $p \rightarrow 0$, the groups $G_{p}$ converge to an isomorphic group $G_{0}$ which acts simply transitively on each of the half-spaces which compose the complement of the affine subspace $x=0$. Choosing a discrete subgroup $\Gamma$ as above, we obtain still another affine structure on the compact 3-manifold $M$. Notice as $p$ varies from positive to negative, the affine manifold $0_{+} \times R / \Gamma$ continuously deforms to the affine manifold $0_{-} \times R / \Gamma$, passing through the structure obtained from $G_{0}$.

It is possible to deform the group $G_{0}$ in another way. Let $G_{0, \lambda}(\lambda \in R)$ be the group of affine transformations 


$$
\left(\begin{array}{ccc}
e^{\lambda s} & 0 & 0 \\
0 & e^{s} & 0 \\
0 & 0 & e^{-s}
\end{array}\right)\left(\begin{array}{l}
0 \\
t \\
u
\end{array}\right)
$$

For $\lambda \neq 0$, this group acts simply transitively on a half-space $\Omega$. For $\lambda=2$, the group $G_{0, \lambda}$ is just the group $G_{0}$ above. By taking discrete cocompact subgroups $\Gamma$, we obtain more affine manifolds (all of which are homeomorphic) $\Omega / \Gamma$. For different values of $\lambda$ these affine structures are distinct.

For more examples of affine structures on these manifolds, the reader is referred to the introduction to Auslander [1], and Fried, Goldman, and Hirsch [3].

Finally we note that most of these examples are "topologically conjugate," i.e., there is a homeomorphism of $R^{3}$ conjugating one group to another. For example, $G_{0,2}$ and $G_{0, \mu}$ are conjugate under the Holder continuous map $(x, y, z) \rightarrow\left(x^{\mu / \lambda}, y, z\right)$, at least if $\lambda$ and $\mu$ have the same sign. All the groups $G_{p}$ are conjugate to $G_{0}$ under the algebraic morphism $(x, y, z) \rightarrow\left(x-p / 2 y^{2}, y, z\right)$. Thus the affine manifolds $0_{+} / \Gamma$ and $0_{-} / \Gamma$ are algebraically equivalent although the behavior of geodesics on them is quite different.

\section{REFERENCES}

1. L. Auslander, Simply transitive groups of affine motions, Amer. J. Math., 99 (1977), 809-826.

2. D. Fried, Closed similarity manifolds, (to appear).

3. D. Fried, W. Goldman and M. Hirsch, Affine manifolds with nilpotent holonomy, (to appear).

4. J. L. Koszul, Sous-groupes discrets des groupes de transformations affines admettant une trajectoire convexe, C. R. Acad. Sc. Paris, 259 (1964), 3675-3677.

5. J. Vey, Sur les automorphismes affines des ouvertes convexes saillants, Annali della Scuola Normale Superiore di Pisa XXIV, Fasc., IV (1970), 641-665.

Received December 11, 1979.

UNIVERSITY OF CALIFORNIA

BERKELEY, CA 94720

AND

UNIVERSITY OF COLORADO

BOULDER, CO 80309 


\section{PACIFIC JOURNAL OF MATHEMATICS}

\section{EDITORS}

DONALD BABBITT (Managing Editor)

University of California

Los Angeles, CA 90024

Hugo RossI

University of Utah

Salt Lake City, UT 84112

C. C. MOORE and ANDREW OGG

University of California

Berkeley, CA 94720
J. DugundjI

Department of Mathematics

University of Southern California

Los Angeles, CA 90007

R. FINN and J. MILGRAM

Stanford University

Stanford, CA 94305

\section{ASSOCIATE EDITORS}
R. ARENS
E. F. BECKENBACH
B. H. NeUmanN
F. WOLF
K. YosHIDA

\section{SUPPORTING INSTITUTIONS}

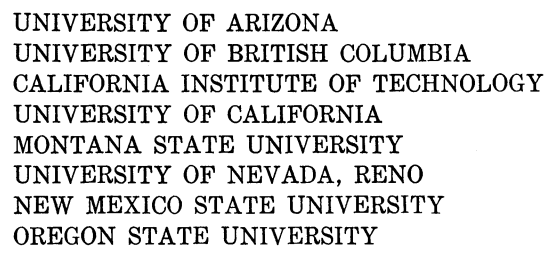

UNIVERSITY OF ARIZONA

UNIVERSITY OF BRITISH COLUMBIA CALIFORNIA INSTITUTE OF TECHNOLOGY

UNIVERSITY OF CALIFORNIA

MONTANA STATE UNIVERSITY

UNIVERSITY OF NEVADA, RENO

NEW MEXICO STATE UNIVERSITY OREGON STATE UNIVERSITY

\author{
UNIVERSITY OF OREGON \\ UNIVERSITY OF SOUTHERN CALIFORNIA \\ STANFORD UNIVERSITY \\ UNIVERSITY OF HAWAII \\ UNIVERSITY OF TOKYO \\ UNIVERSITY OF UTAH \\ WASHINGTON STATE UNIVERSITY \\ UNIVERSITY OF WASHINGTON
}

The Supporting Institutions listed above contribute to the cost of publication of this Journal, but they are not owners or publishers and have no responsibility for its content or policies.

Mathematical papers intended for publication in the Pacific Journal of Mathematics should be in typed form or offset-reproduced, (not dittoed), double spaced with large margins. Please do not use built up fractions in the text of the manuscript. However, you may use them in the displayed equations. Underline Greek letters in red, German in green, and script in blue. The first paragraph or two must be capable of being used separately as a synopsis of the entire paper. Please propose a heading for the odd numbered pages of less than 35 characters. Manuscripts, in triplicate, may be sent to any one of the editors. Please classify according to the scheme of Math. Reviews, Index to Vol. 39. Supply name and address of author to whom proofs should be sent. All other communications should be addressed to the managing editor, or Elaine Barth, University of California, Los Angeles, California, 90024.

50 reprints to each author are provided free for each article, only if page charges have been substantially paid. Additional copies may be obtained at cost in multiples of 50 .

The Pacific Journal of Mathematics is issued monthly as of January 1966. Regular subscription rate: $\$ 102.00$ a year (6 Vols., 12 issues). Special rate: $\$ 51.00$ a year to individual members of supporting institutions.

Subscriptions, orders for numbers issued in the last three calendar years, and changes of address shoud be sent to Pacific Journal of Mathematics, P.O. Box 969, Carmel Valley, CA 93924, U.S.A. Old back numbers obtainable from Kraus Per!odicals Co., Route 100, Millwood, NY 10546.

\section{PUBLISHED BY PACIFIC JOURNAL OF MATHEMATICS, A NON-PROFIT CORPORATION}

Printed at Kokusai Bunken Insatsusha (International Academic Printing Co., Ltd.). 8-8, 3-chome, Takadanobaba, Shinjuku-ku, Tokyo 160, Japan.

Copyright (C) 1981 by Pacific Jounal of Mathematics Manufactured and first issued in Japan 


\section{Pacific Journal of Mathematics}

Vol. 94, No. $2 \quad$ June, 1981

Thomas E. Armstrong and William David Sudderth, Nearly strategic

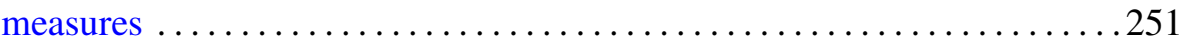

John J. Buoni, Artatrana Dash and Bhushan L. Wadhwa, Joint Browder

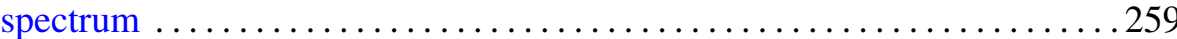

Jack Paul Diamond, Hypergeometric series with a $p$-adic variable . .......265

Raymond Frank Dickman, Jack Ray Porter and Leonard Rubin,

Completely regular absolutes and projective objects ............ 277

James Kenneth Finch, On the local spectrum and the adjoint ........... 297

Benno Fuchssteiner, An abstract disintegration theorem ............ 303

Leon Gerber, The volume cut off a simplex by a half-space $\ldots \ldots \ldots \ldots 311$

Irving Leonard Glicksberg, An application of Wermer's subharmonicity

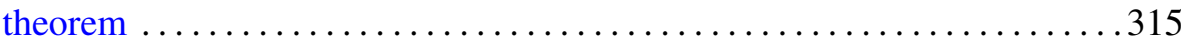

William Goldman, Two examples of affine manifolds ............... 327

Yukio Hirashita, On the Weierstrass points on open Riemann surfaces .....331

Darrell Conley Kent, A note on regular Cauchy spaces ............. 333

Abel Klein and Lawrence J. Landau, Periodic Gaussian

Osterwalder-Schrader positive processes and the two-sided Markov

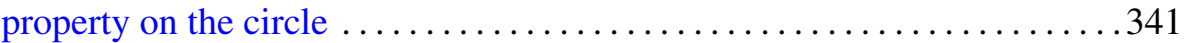

Brenda MacGibbon, $\mathscr{K}$-Borelian embeddings and images of Hausdorff

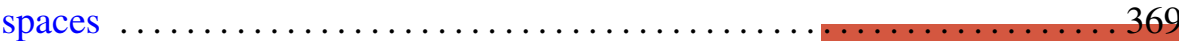

John R. Myers, Homology 3-spheres which admit no PL involutions . . . . . 379

Boon-Hua Ong, Invariant subspace lattices for a class of operators . . . . . 385

Chull Park, Representations of Gaussian processes by Wiener processes . . . 407

Lesley Millman Sibner and Robert Jules Sibner, A sub-elliptic estimate

for a class of invariantly defined elliptic systems $\ldots \ldots \ldots \ldots \ldots \ldots .417$

Justin R. Smith, Complements of codimension-two submanifolds. III.

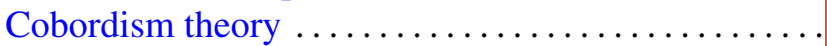

William Albert Roderick Weiss, Small Dowker spaces

David J. Winter, Cartan subalgebras of a Lie algebra and its ideals. II ... 